\title{
Research and Analysis of a Real Estate Virtual E-Commerce Model Based on Big Data Under the Background of COVID-19
}

Delong Zhu, Anhui Institute of Information Technology, Wuhu, China

\begin{abstract}
The sudden attack of the new coronavirus in 2020 has brought an unprecedented impact on the real estate market economy and has completely disrupted people's work and life rhythms! With the rapid development of the internet, the internet has penetrated into all aspects of people's lives. As soon as e-commerce was introduced, it was loved by the majority of young people and brought tremendous changes to people's lives. As an important pillar industry of the national economy, real estate lacks a better e-commerce model and is still in the traditional sales model, waiting for customers to come. With the advent of the era of big data, breakthroughs in IT technology have made the collection, analysis, and processing of big data a reality, which makes it possible for big data to provide guidance for the development of e-commerce. As traditional processing technologies and ways of thinking gradually fail to meet application requirements, people have reached a consensus that big data will trigger the next revolution in the e-commerce industry, and how to make the real estate industry develop better in this revolution has become a reality. Based on this, this paper studies a real estate virtual e-commerce model based on big data. In the study of this model, this paper combines the advantages of e-commerce and virtual communities to design a more effective virtual e-commerce model that collects the data of virtual e-commerce platforms for analysis and processing, accurately obtains the needs of customers, provides customers with more reasonable options to meet their needs, and promoted the healthy development of the real estate industry. The analysis of e-commerce and virtual communities shows that the virtual e-commerce model designed in this paper is a more effective model, and the real estate virtual e-commerce model based on big data technology can serve the real estate industry and do a good job in the sales reform of the real estate industry.
\end{abstract}

\section{KEYWORDS}

Big Data, COVID-19, E-Commerce, Real Estate, Virtual Community

\section{INTRODUCTION}

In e-commerce, socialization is not only to strengthen the connection between buyers and sellers, but also to strengthen the degree of interconnection between consumers. E-commerce platforms are adding more and more social functions on the mobile terminal, which effectively increases the frequency of users opening applications. Social elements increase the user stickiness of the e-commerce platform. When the number of openings is greater, the possibility of purchase is higher, which means that the ability to monetize attention resources is stronger (Fatima et al., 2017). Social elements such as live

DOI: 10.4018/JOEUC.20211101.oa5

This article published as an Open Access article distributed under the terms of the Creative Commons Attribution License (http://creativecommons.org/licenses/by/4.0/) which permits unrestricted use, distribution, and production in any medium, provided the author of the original work and original publication source are properly credited. 
broadcasts, asking everyone, and buyer comments give users a sense of joy and respect, and promote users to actively search for information and products. They also use virtual attention to attract more virtual attention resources. Virtual attention resources, like other resources, are limited, scarce and important (Nantembelele \& Gopal, 2018). On the one hand, attention intention occupants continue to improve their socialization and launch new products, absorb and stick virtual attention with visual elements, and various virtual attention products have appeared. On the other hand, buyers are also gaining the virtual attention of other users through social forms such as evaluation and asking everyone. In the e-commerce market where commodity information is exploding, in order to obtain more attention resources, the attention-intent holders need to increase the amount of information disseminated, and absorb virtual attention from all parties through different dissemination methods and means (Wei \& Ho, 2019).

For the relationship between the two important components of social e-commerce, social and e-commerce, scholars have conducted a more in-depth discussion (Munshifwa et al., 2018). Ickler $\mathrm{H}$ and Schülke $\mathrm{S}$ believe that social e-commerce is a website that combines business and user interaction through information technology to develop business. Dennison G, Bourdage-Braun S, Chetuparambil M. believe that social e-commerce is an e-commerce transaction activity completed by social networks using network technology, and it is a collection of word-of-mouth communication and e-commerce, and a combination of consumers and businesses. Stephen and Toubia proposed a similar definition, believing that it is Internet-based social media, which allows users to actively participate in the sales and marketing of products and services in the market or in virtual communities (Kim, 2019). Marsden pointed out that social e-commerce has three characteristics: word of mouth, recommendation and friend assistance. Zhao Huang et al. further pointed out that social e-commerce is a commercial platform, which is based on social media and technologies that support society and user contributions, and helps consumers to make better decisions by providing product and service information (Liu \& Zhan, 2018). According to the needs of different merchants and users, a variety of product virtual display methods have been realized, including the panoramic model display method based on product images; the three-dimensional interactive model method based on product graphics; the product display method based on pictures; and corresponding products are provided separately Show the design method of the model (Bauer, 2018).

Ji Xiang believes that the e-commerce model of blog combines social networks. Wang Lepeng and others gave four strategies for the integration of social networking sites and e-commerce, including using word-of-mouth marketing to guide users' consumption behavior. Xu Cuiping proposed that social platforms provide e-commerce with new outlets and tools for cultivating user loyalty, and this combination brings direct benefits to enterprises (Luo, 2018). Li Qiaodan pointed out that active social interaction can drive the development of e-commerce. The State Administration for Industry and Commerce proposed for the first time that social e-commerce should be included in supervision. Social e-commerce is the integration product of social media and e-commerce to a certain stage. This article will analyze the term social e-commerce (Peng et al., 2018). In the domestic communication circles, some scholars have put forward the viewpoints of "influence economy", "eyeball economy" and "public opinion economy" based on the concept of attention economy, but the academic circles generally accept that "the basis of media economy is attention economy" and pay attention Power economy is a more essential term. The significance of this platform is to meet consumers' higher demand for product browsing (Yong-zhang et al., 2017). Consumers can fully understand the product through human-computer interaction to increase the consumer's one-time shopping success rate, thereby increasing The credibility and efficiency of e-commerce can reduce the economic loss and time waste caused by return and exchange; for merchants, it can not only increase product sales, but also can effectively solve many small and medium-sized enterprises by renting supporting production platforms (Xiao et al., 2017). The human, material and financial problems faced by enterprises and individual merchants in developing e-commerce; for cloud platform service providers, renting out 
software and hardware resources can not only recover costs, but also maximize resource utilization (Nezami et al., 2018).

The virtual product display and real estate e-commerce platform based on the big data platform are composed of two parts. One is the product virtual reality model display and the real estate e-commerce platform. In addition to providing normal online real estate e-commerce transaction platforms for consumers to browse products, purchase products, In addition to basic functions such as order management, merchants upload products, manage products, order management, and webmaster background management, it also needs to provide a three-dimensional interactive model display function of virtual products. The other part of the platform is to provide a dedicated product virtual reality model design platform for merchants (Gui et al., 2019). The platform needs to have the software and hardware conditions required to make models, provide customized systems to meet the individual needs of users, and ensure that each merchant enjoys unique resources. Ensure data security. This article focuses on the analysis of socialized real estate e-commerce as the research object, and conducts research around virtual attention from the perspective of communication. The thesis first discusses the two concepts of socialized real estate e-commerce and virtual attention, so as to establish a clear and accurate understanding of them; secondly, it discusses the accumulation, development, and exchange of attention resources by the attention subjects of real estate e-commerce. . Thirdly, in order to seek more attention resources, not only strengthen the social elements in the platform, but also carry out social layout, link with social software, and keep warm.

\section{THE CONSTRUCTION OF VIRTUAL E-COMMERCE MODE}

\subsection{Definition and Classification of E-Commerce}

From a broad perspective, the vast majority of people in the current society are more or less in contact with e-commerce, are enjoying the high-speed development of e-commerce brought about by the improvement of quality of life. Because people's understanding of e-commerce is not in-depth, incomplete, and engaged in various industries, different people from all walks of life combined with their own understanding, from their own point of view for e-commerce under many different definitions. ICC believes that the main feature of e-commerce is that the parties involved in the transaction do not conduct face-to-face transactions, but conduct business activities through telephone, fax, Internet and other means that are not directly contacted (Navarro-Méndez et al., 2017). At the same time, ICC pointed out that the combination of various modern information technologies represented by network communication, data collection and data processing should be the technical characteristics of e-commerce.

According to the European Parliament, e-commerce refers to business activities carried out by electronic means, which uses modern communication technology for data exchange and processing, including audio, video, text, etc. E-commerce involves a lot of contents, including digital trade, data transmission and electronic payment, as well as electronic certificate, identity authentication, data encryption, electronic signature and other security means.

The International Economic Cooperation Organization (OECD) believes that the business transactions between enterprises or between enterprises and users through the Internet are collectively referred to as e-commerce. The U.S. government believes that if all aspects of business activities are conducted through the Internet, it is e-commerce. General Electric Company of the United States defines e-commerce as follows: all transactions conducted by electronic means are called e-commerce, which is divided into inter enterprise and inter enterprise and user e-commerce. According to HP, the characteristic of e-commerce is to build a link between enterprises and consumers through electronic means. The virtual model of real estate e-commerce is shown in Figure 1.

From the aspects of operation mode, activity content, transaction scope, network type, business mode, transaction object, etc., e-commerce can have many classification methods, such as complete or incomplete, direct or indirect, regional or global, local area network or Internet (Zhu \& Zhong, 

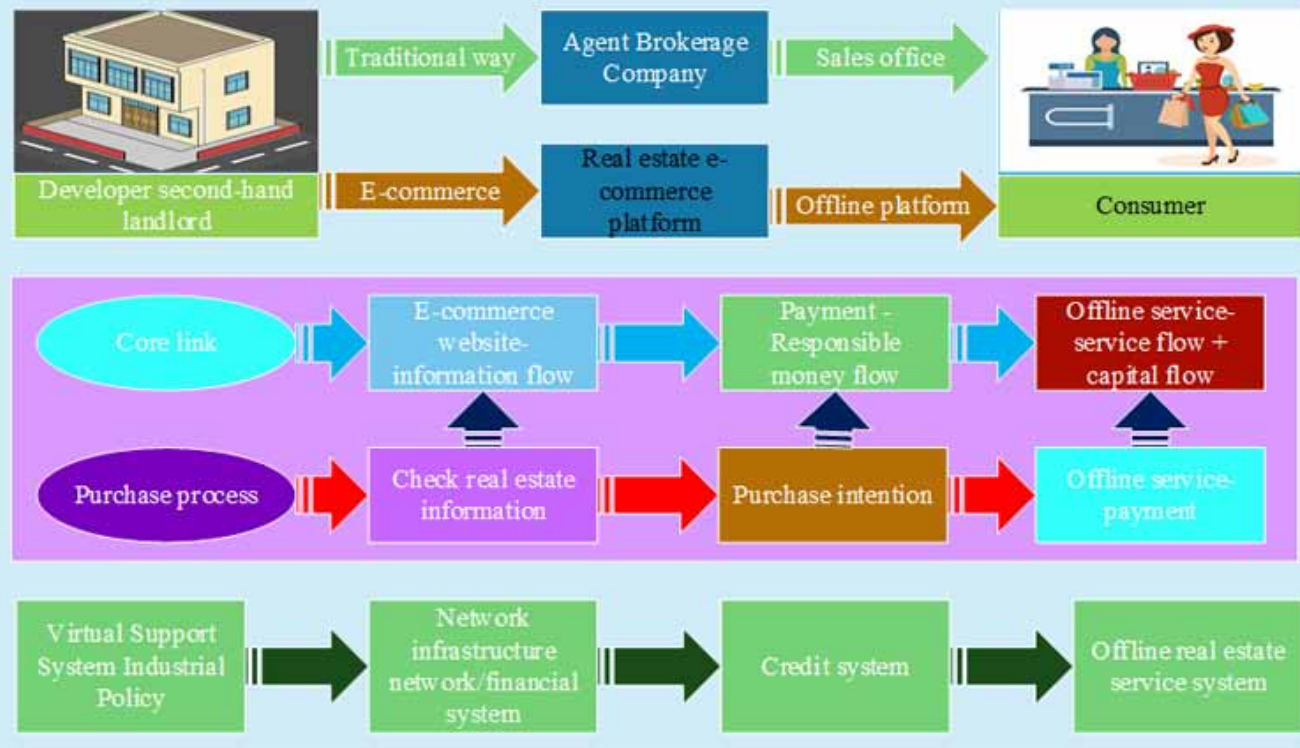

2017). The characteristics of real estate e-commerce. The real estate-based e-commerce has become a part of the attention economy because it has the four characteristics of the attention economy: First, the information explosion is further intensified due to commercial competition, which increases the difficulty of obtaining attention. And this more competitive market, huge market size, small market barriers and product differentiation make attracting virtual attention a magic weapon for the intent of the attention holder. The second is the trend of economic dematerialization. Attention providers use e-commerce applications to no longer merely satisfy material needs. Among them, dematerialized needs such as knowledge economy and real estate experience are on the rise. The third is the highly developed media. In the process of real estate of e-commerce, the media has developed rapidly, especially self-media, which has become an important place of production, exchange and consumption of virtual attention in this economy. Fourth, people are spending more and more time on it, and user attention behavior has become an important daily behavior. Even the vast majority of real life can be replaced by virtual networks.

\subsection{Definition and Classification of Virtual Community}

When the information is rapidly expanding, the audience's attention is relatively tightened, and virtual attention becomes a scarce resource. The intentional occupant of attention must spend a lot of effort and invest more resources to obtain the limited virtual attention on the platform (Otterness, 2017). We believes that the important thing is not the number of daily audience information contacts, but how much information gets the audience's attention. Therefore, the intentional occupant of attention needs to spread attention products through effective channels and methods. Only through the beautiful outer packaging of attention products can it attract virtual attention and obtain the audience's continuous attention through rich connotations. Under the pressure of competition, the intentional occupants of attention have fraudulent behaviors, and they intend to attract virtual attention resources through false attention packaging without substantial content (Bhadoria \& Chaudhari, 2019; Li et al., 2017).

With the continuous maturity of virtual communities, different types of virtual communities have emerged according to different characteristics. Although previous scholars put forward many specific 
Table 1. Classification of virtual communities

\begin{tabular}{|l|l|}
\hline Classification standard & Types of virtual communities \\
\hline Member demand & $\begin{array}{l}\text { Transactional community, interest community, fantasy community and relationship } \\
\text { community }\end{array}$ \\
\hline Mode of operation & Entertainment community, hobby community, e-commerce community \\
\hline Interactive prescription & Asynchronous and synchronous communities, and hybrid synchronization \\
\hline Support technology & Mailing lists, chat rooms, bulletin boards, newsgroups, multiuser spaces \\
\hline Value analysis & Transactional community, thematic community \\
\hline
\end{tabular}

types according to different research perspectives, so far there has not been a widely recognized standard. Through the summary of literature, the classification of virtual communities is as follows, as shown in Table 1. In social e-commerce, audiences are the most important social providers of virtual attention. They are not only consumers of media products, but also attention traders and labourers. They consume network media products and pay virtual attention during the consumption process, on the one hand, in exchange for their own corresponding satisfaction, on the other hand, they endow the product with economic value. There is a sentence from Schraw that explains this very well.

\subsection{Discussion on the Feasibility of Real Estate Virtual E-Commerce Model}

This paper classifies all kinds of domestic e-commerce websites, and obtains PageRank values of all kinds of domestic well-known e-commerce websites' home pages and virtual community pages from the Internet, and makes correlation analysis and chi square analysis of PageRank values of all kinds of websites' home pages and virtual community pages. Through the correlation analysis, we can get the types of websites which are suitable for the establishment of virtual community, and explain the feasibility of virtual e-commerce model and its application in the real estate industry. Through the literature research on the economic characteristics of virtual community and the value of website, we can see that there is a relationship between virtual community and website. In this paper, value will be the main object of analysis, to study the correlation between various e-commerce websites and their virtual communities. We find the impact of virtual communities on the e-commerce main station. At the same time, the virtual community form of all kinds of e-commerce is adjusted to a certain extent (Li et al., 2018).

The service provider of the online trading platform is mainly engaged in the operation of the online trading platform and provides trading services for the seller and the buyer, as well as a computer network system providing network space, information technology and trading services for all kinds of online transactions. As a result, the virtual community, as the interaction between the buyer and the seller, has a certain impact on the growth of the website. Therefore, this paper puts forward the hypothesis 1: there is a positive correlation between the service provider of online trading platform and the development of its BBS / blog / message board.

Online transaction assistant service provider, in order to optimize the online transaction environment and promote online transactions, provides security certification, credit evaluation, online payment, logistics distribution, transaction insurance and other services for the seller and the buyer (Kovalchik \& Reid, 2017; Liang et al., 2018). As a result, the online transaction support service provider has low interactive requirements for the communication between the buyer and the seller, and the communication needs of the buyer and the seller are weak, so this paper puts forward the hypothesis 2: there is a negative correlation between the development of the online transaction support service provider and its BBS / blog / message board.All kinds of e-commerce websites have different characteristics and different requirements for virtual communities. The development of social e-commerce benefits from the attraction and maintenance of virtual attention resources by 
social media and the increase in user electronic consumption. In traditional mass media, audience measurement and media management are divided under different subjects, but in social e-commerce, both can be operated on the same platform. The platform uses big data technology to first gather and package virtual attention according to certain rules, and then sell virtual attention resources to the attention intention holders, and charge different fees according to the quality of the virtual attention resources (Losing et al., 2018).

\section{THE APPLICATION OF BIG DATA AND VIRTUAL E-COMMERCE NETWORK IN REAL ESTATE}

\subsection{Big Data Overview}

Applying big data analysis, real estate companies can filter the information they need, accurately obtain customer needs, and lock in the scope of customers, which is of great help for companies to formulate development plans, revise marketing strategies, and reduce marketing costs. For the research and forecast of the real estate market, big data analysis can be applied but not limited to the following aspects:

(1) Research on the macroeconomic situation. Find the data sequence closest to the current situation in the existing real estate cycle database and conduct correlation analysis. It can be used to help discover the intersections and connections between various factors and the real estate week, and guide the prediction of the current macro situation of the market.

(2) Research on market development trends. Analysis factors include data indicators such as general market conditions, development level dynamics, market share, etc., to obtain conclusions to assist business decision-making.

(3) Research on real estate supply. Comprehensive population current housing conditions and location distribution, regional land use status, government policy planning and existing real estate supply information, analyze the regional real estate supply forecast and development plan.

(4) Customer research. Multi-dimensional association and sequence pattern analysis of customer information. Collect and analyze customer consumption behavior patterns, preferences, consumption habits and other data, predict their needs, and find opportunities and ways to affect customer behavior.

\subsection{Steps of Real Estate Precision Marketing Based on Big Data Virtual E-Commerce Network}

It is easy to generate different needs in the face of various customers, and these needs form a huge amount of big data of user needs. If the demand data can be handled well, the sales will have the opportunity to understand the customer's hobbies and habits, plan to make the customer more satisfied with the precise marketing plan, and achieve better understanding of the customer than "the customer himself'. In the traditional sales mode, it is difficult to make statistics on customers' needs and achieve accurate sales, let alone follow-up data processing. But with the rise of e-commerce platform (Prisha et al., 2017) and virtual community (Otterness, 2017), there is a theoretical basis for collecting customer information, which is no longer empty talk.

(1) Collection of customer demand data. In the second chapter, this paper discusses the feasibility of building a virtual e-commerce platform. The virtual e-commerce model is not only the communication between the company and customers, but also the communication platform between customers. The data exchanged between customers is more valuable than the data exchanged between the company and customers, and it is also an important source of data collection. 
(2) Processing of customer demand data. Through the virtual e-commerce platform to get the data of customer demand, we need to process the data through big data technology, extract the customs data of customer demand, and accurately position and analyze the customer, so as to develop a sales plan more in line with customer demand.

According to the similarity degree of customer characteristics, customers are divided into several sub groups, and the internal characteristics of each group are similar, but there are obvious differences between groups. Only when different customer groups are distinguished, can targeted precise marketing be carried out, research and development be carried out, and products and services corresponding to customers are provided. Without big data support, traditional analysis methods, such as demographic factors and geographical factors, can only provide a fuzzier customer profile, and cannot achieve the true sense of customer segmentation, which makes precision marketing unable to carry out smoothly. Big data analysis can screen out valuable information from massive, complex and unrelated customer data. It is the mainstream method in the field of customer segmentation to accurately analyze and judge customer behavior mode and value through precise segmentation technology. In particular, the variable elements of customer analysis are not immutable and need to be updated and optimized at any time according to market changes.

According to the evaluation results of customer value, the value orientation of customers is carried out and the classification of customer grade is determined. The variables of customer value orientation include: current living conditions of customers, family population composition, occupational characteristics, annual family income, purchase demand, source channel, and etc. According to the different real estate projects, the customer value, customer positioning and project matching are selected to form a customer system.

(3) Customer analysis. According to the customer segmentation and positioning, cross analyze the customer's own situation; find the customer characteristics and habits, so as to further carry out the implementation of precision marketing for their individual.

1. Marketing plan development. Through the analysis of the existing data, after getting the characteristics of different customer groups, we should combine the needs of enterprises, and make targeted marketing plans for each customer group. In the process of making marketing plans, we need to have phased marketing objectives. Such as cross selling and increasing the number of customers.

2. Marketing effect feedback. After the implementation of the marketing plan, various types of data in the process shall be summarized and analyzed, the advantages and disadvantages of the marketing activities shall be evaluated, the problems shall be optimized and improved, and the formulation of the marketing plan and the development of the marketing activities in the next stage shall be guided.

\subsection{Model Building}

The model of real estate precision marketing based on big data virtual e-commerce network designed in this paper is shown in Figure 2. It can be seen from the figure that the traditional sales mode still exists. As can be seen from the figure, real estate companies develop a virtual e-commerce platform, in which they can realize the communication between companies and customers, customers and customers, and then use the information collection and processing module to collect and process customer demand data. The real estate company uses this data to develop a sales plan to improve the traditional sales model and push the line to customers. The problems generated in the process of pushing the line can be fed back to the system. The company optimizes the system for the problems 
Figure 2. Model of real estate precision marketing based on big data virtual e-commerce network

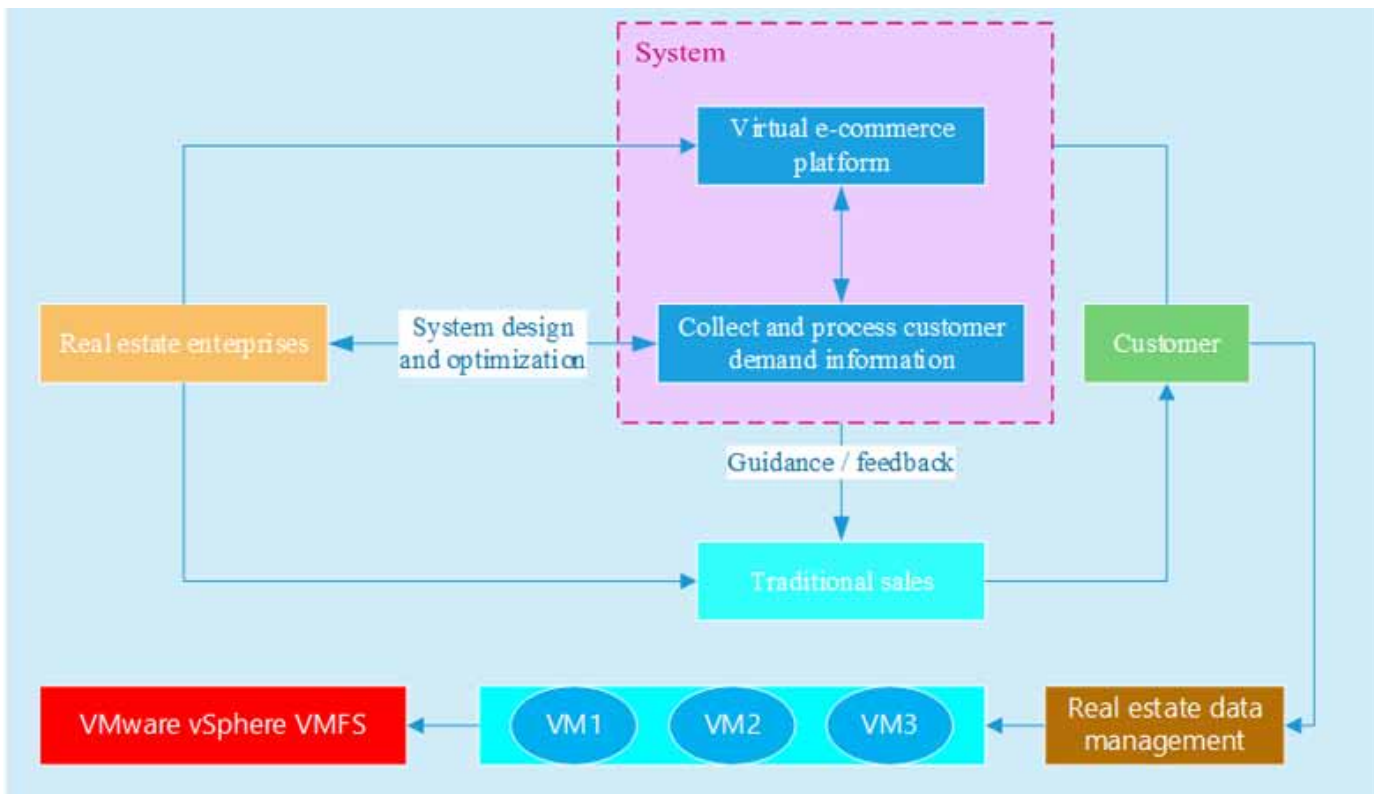

generated, collects and processes customer information again, and develops a plan to sell to customers. This mode of collecting information, making plans, sales, feedback, optimizing system and collecting information can be kept circulating, constantly improving the performance of the system, collecting and processing customer demand information more pertinently, realizing better understanding of customers, so as to better realize sales and promote the development of the real estate industry.

\section{SIMULATION ANALYSIS AND DISCUSSION}

\subsection{Feasibility Analysis}

At present, many real estate companies use traditional sales methods, but there is very little to improve traditional sales methods by using e-commerce. It is necessary to discuss the role of using e-commerce platform to improve sales methods. Figure 2 shows the increasing returns of the network industry. In economics, the manufacturer infers that the profit of the manufacturer is the price deducting cost (p-Mc) according to the assumption of WTP (willingness to pay) Pricing of the user. As can be seen from Figure 3, the gap between wtp-mc and the network industry will increase with not only the number of consumers, but also the number of clients. Therefore, the profit of manufacturers in the network industry (P-MC) can be represented by a concave upward curve, which will become the increasing return of the network industry. This phenomenon shows that with the increasing number of users, the profits of manufacturers are increasing.

After analyzing the phenomenon of increasing returns in the network industry, Figure 4 shows the transaction quota and year-on-year growth proportion of China's e-commerce in recent years. Find the main needs of customers through customer demand analysis and prediction, and guide the formulation of product design and marketing strategies. On the basis of making full use of the company's existing customer historical data, increase the outsourcing of the H-party company, first analyze the needs of geographical customers (living, work, and dealing with the project area), and get more customer analysis related Data, and then this method is extended to the radiation area and the external training area. 


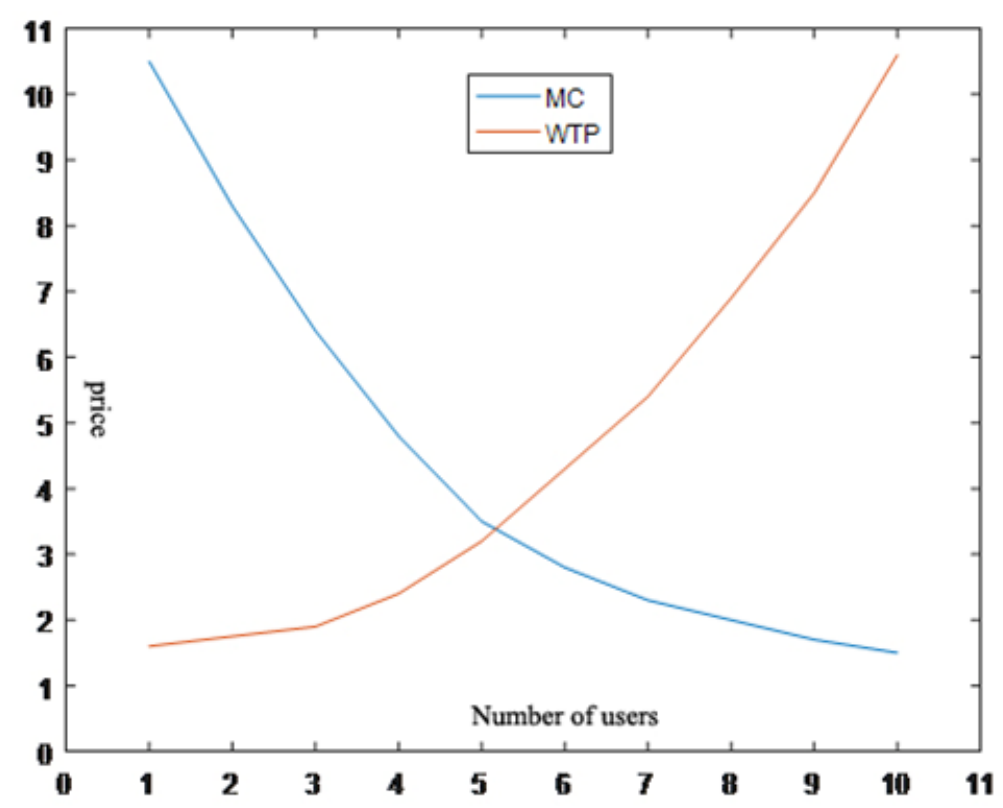

Accurate grasp of customers is not a one-time classification, but needs to be dynamically adjusted according to the needs of the enterprise, and gradually lock in the common nature and characteristics of customers. For example, the existing 2-level customer classification system is further refined to the third level, and customer labels are implemented from different dimensions such as area demand, purchase intention, purchasing ability, and purchase time. According to the different concerns of customers for real estate products, customers are divided into different types of purchase groups, such as product type, building quality, community landscape facilities, living facilities, education facilities, property management level, and community appreciation space (Figure 5). Through cross-analysis with the previous classification levels, discover and judge the true purchase needs and characteristics of customers, and realize the understanding and analysis of different groups of customers. And because of the traditional concept that marriage needs to buy houses in China, the demand for houses in this age group is the largest, and it is also the main source of housing purchase in the real estate market. These show that the traditional sales method of real estate improvement by e-commerce is supported by user sources.

In Section 2.3, in order to explore the feasibility of real estate virtual e-commerce model, this paper makes some assumptions. These assumptions are mainly to analyze whether there is a positive correlation of e-commerce websites in the real estate industry, so as to judge the feasibility of establishing a virtual e-commerce model. With the help of some existing e-commerce websites and virtual communities, this paper calculates the correlation between virtual communities and e-commerce in Figure 6. It can be seen from the figure that there is a good correlation between $\mathrm{C} 2 \mathrm{C}$ mode of e-commerce and message board of virtual community, which shows that $\mathrm{C} 2 \mathrm{C}$ and message board can be well combined to establish a virtual e-commerce mode. $\mathrm{C} 2 \mathrm{C}$ is a consumer to consumer e-commerce application mode. In the real estate industry, the established e-commerce mode needs more discussion between customers. The discussion information between customers has a higher credibility and is a reliable source of customer demand data. 
Journal of Organizational and End User Computing

Volume 33 •Issue 6 • November-December 2021

Figure 4. Transaction data of China's e-commerce market

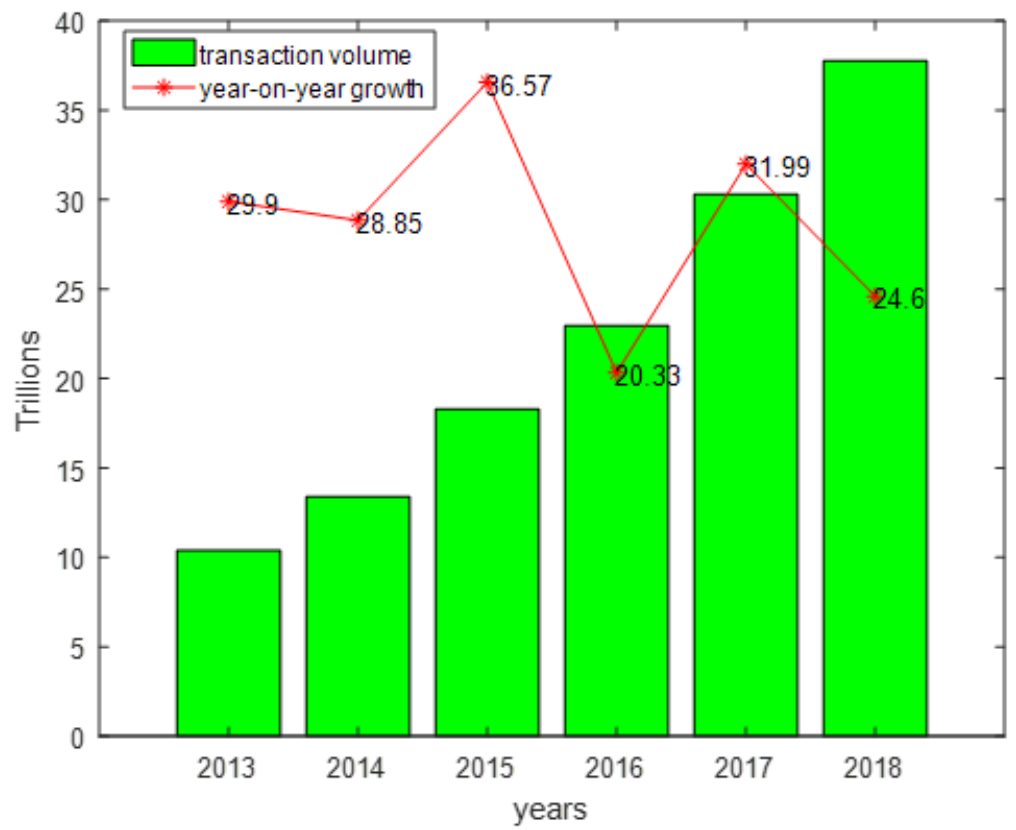

Figure 5. Age distribution of e-commerce users

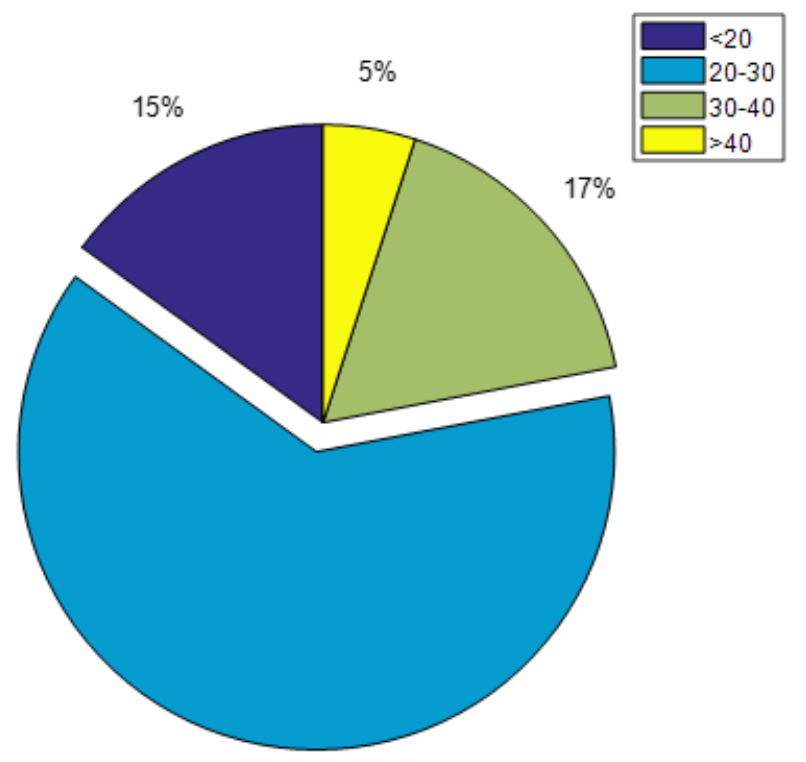

$63 \%$ 


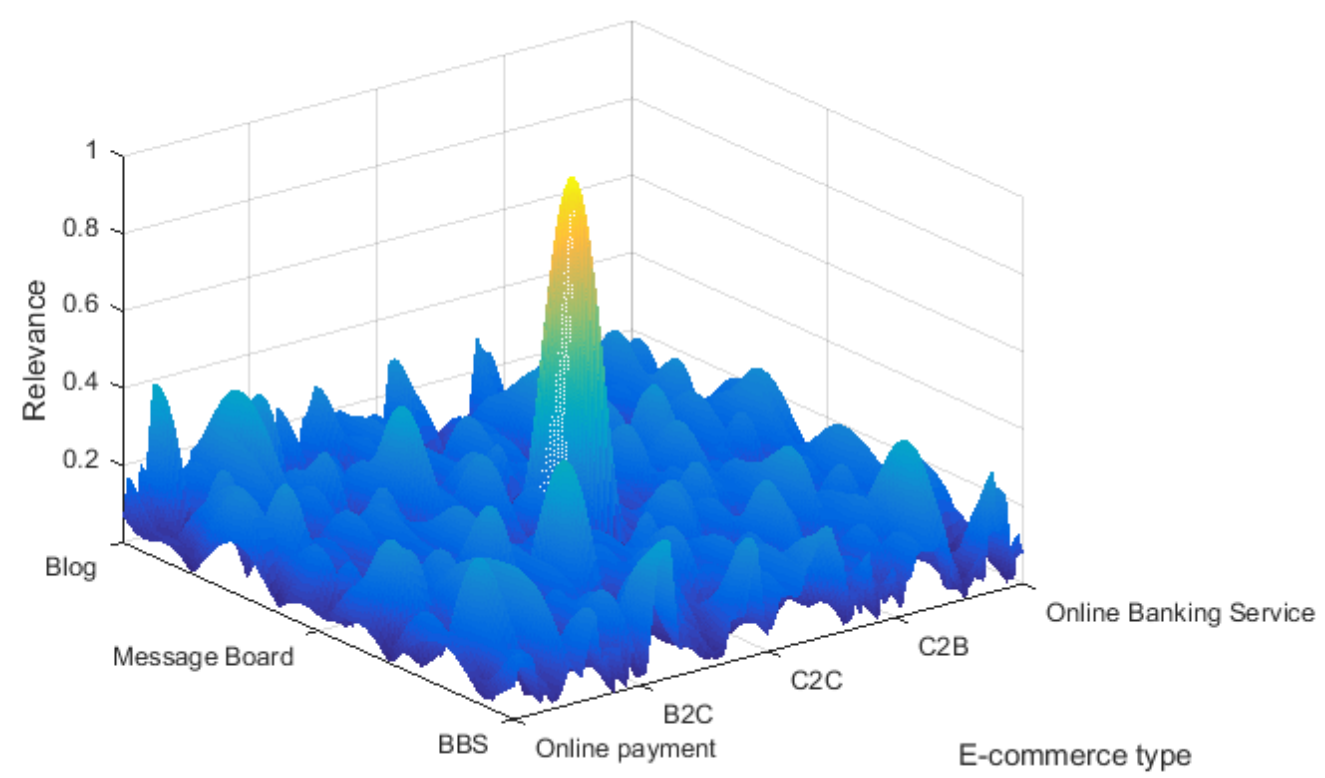

Virtual community type

To sum up, this paper analyzes the network profit, which shows that the profit of the network market is huge; then it analyzes the transaction volume and the year-on-year growth of e-commerce, which shows that the development trend of e-commerce market is good, and there is full room for real estate investment; The main users of e-commerce are mainly 20-30 years old, which is the main source of real estate purchase, which also represents that the real estate industry has a huge potential user base in the e-market; Finally, the correlation between e-commerce and virtual community is analyzed, which shows that $\mathrm{C} 2 \mathrm{C}$ has a good positive correlation with virtual community, and can build a virtual e-commerce platform, while $\mathrm{C} 2 \mathrm{C}$ has a good application prospect in the real estate industry.

\subsection{Application Effect Analysis}

In order to get the simulation data, this paper cooperates with a real estate company, which marches into real estate from other industries. The annual sales growth rate is only $21.5 \%$, and the sales rate and market share are low. Non famous real estate companies can avoid the analysis interference caused by fame. The most real analysis results show the application effect of the virtual e-commerce model based on big data in real estate industry. Table 2 shows the company's sales profit margin in 2017 and 2018. It can be seen from Table 2 that in the first quarter, the company's sales profit margin is not high, because the platform has just been built, the popularity is not high, and the information collected is not high. In the second quarter, with the increase of information collection, the sales profit margin generated by using the virtual e-commerce platform based on big data increased, which also exceeded the sales profit margin in 2017. The fourth quarter is the off-season of sales. The sales profit margin generated by using the virtual e-commerce platform based on big data is not much different from the peak season of the second quarter, which is 0.09 higher than the sales profit margin of the fourth quarter of 2017, nearly double. It can be seen that the use of virtual e-commerce platform based on big data can promote the growth of sales profit and the development of real estate companies. 
Table 2. Sales profit margin of a company before and after using this platform

\begin{tabular}{|l|l|l|}
\hline Month & $\mathbf{2 0 1 7}(\%)$ & $\mathbf{2 0 1 8}(\%)$ \\
\hline $1-3$ & 80 & 2 \\
\hline $4-6$ & 16 & 21 \\
\hline $7-9$ & 12 & 17 \\
\hline $10-12$ & 10 & 19 \\
\hline
\end{tabular}

In addition, this paper makes statistics on the monthly sales turnover rate, and shows the comparison results between the traditional sales method and this method as shown in Figure 7. This is because the product just came out and cannot be trusted by customers. With the development of advertising and other marketing methods, the products began to gain the trust of customers, and the turnover rate rose month by month, reaching the maximum in June, is 65.4\%. In July and August, with the coming of the sales off-season, the turnover rate decreased, but in September, October and November, when the sales peak season came, the turnover rate continued to rise. In the overall comparison, except for the first three months, due to the low popularity of the product, it has not been recognized by customers, resulting in low transaction rate. In other months, the sales turnover rate generated by using the big data based virtual e-commerce model proposed in this paper is higher than that of traditional sales methods, which shows that the virtual e-commerce model proposed in this paper can achieve accurate sales and achieve better sales results.

Figure 7. Comparison of sales turnover rate of the two methods

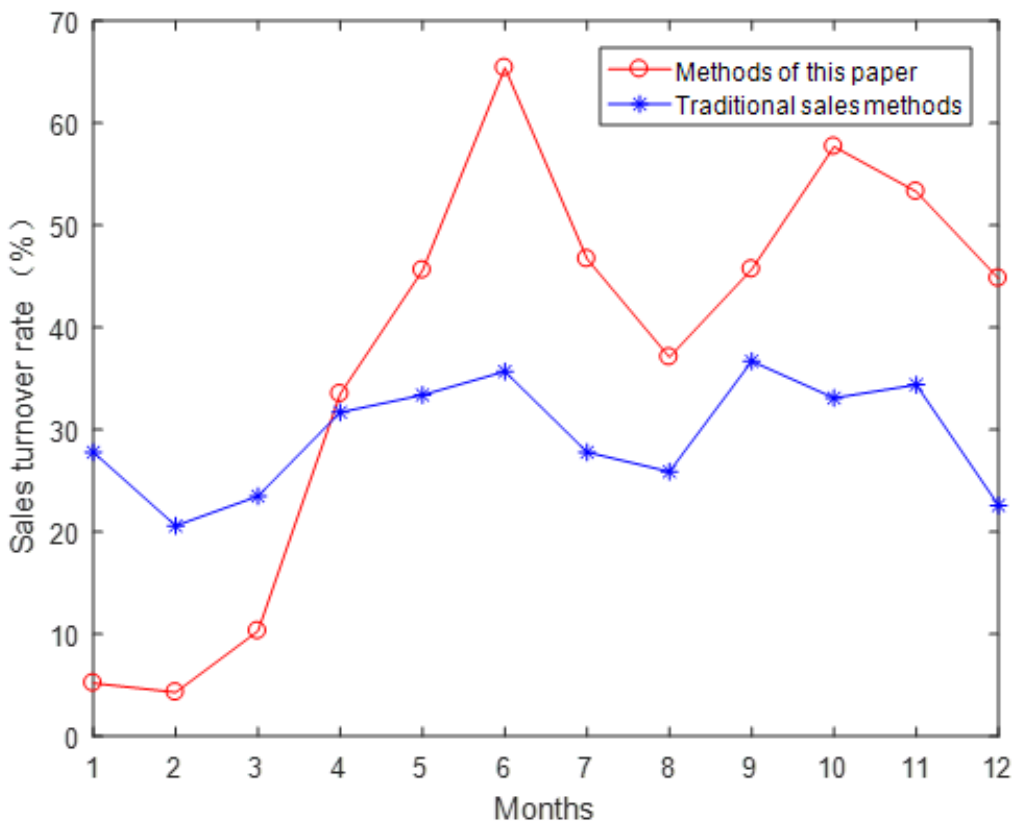




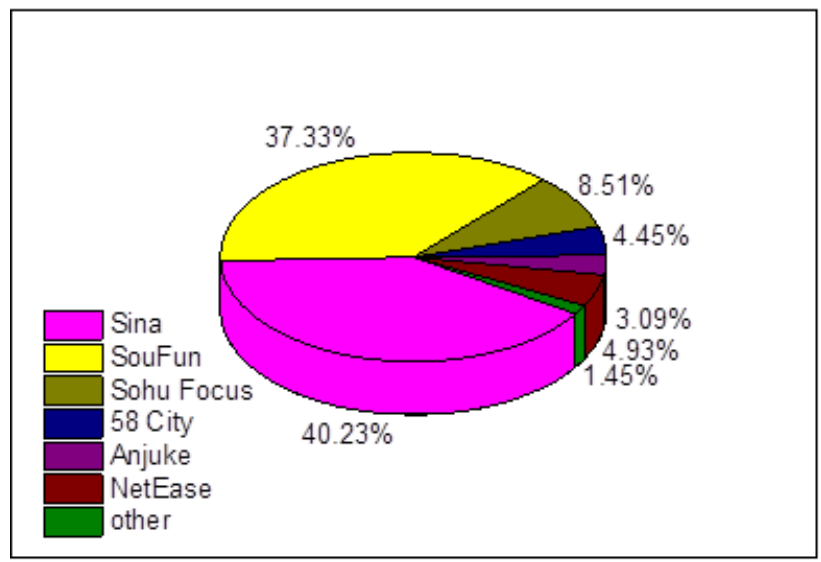

\subsection{Model Effect Analysis}

Social networking is an important part of social e-commerce, supplementing the lack of user participation and interaction in traditional e-commerce, bringing users more personalized service experience, and activating the virtual attention flow of social e-commerce. Social media has two major characteristics, user content creation and user interaction. Social e-commerce removes the clear boundaries between e-commerce and social media, so users have more opportunities to share product information and shopping experience with friends; merchants can use these two characteristics of social media to carry out viral communication and word-of-mouth marketing. It can maintain customer relationships and provide convenience for transactions. Data collection requires long-term development and accumulation, and long-term smooth linkage with various data platforms, and the impact on marketing effects also has a certain lag. Real estate companies are among the local development companies that have started to build a customer database earlier. The model analysis results are shown in Figure 8.

The changes brought about by the Internet are bringing companies and customers closer together. This requires a more in-depth understanding of the details of customer needs and more rapid response to changes in customer needs. The Internet provides more efficient tools for this. The use of the Internet is the only way in this era. If real estate companies cannot adapt to this change, they will be eliminated. But in the Internet age, you should do your own main business, because the meaning of the existence of an enterprise is to create value for customers, which is the eternal business logic.

\section{CONCLUSION}

The combination of real estate and big data is to integrate the company's own internal and external, cooperative channel platforms and data obtained from the entire network, so that the sleepy and seemingly unrelated data can play its value and make decisions and forecasts more accurate. Its application scope can cover the entire industrial chain of real estate development and operation, including: preliminary assessment and positioning, land acquisition, project positioning, project design, landscape planning, cost control, construction management, sales and investment, property services and property value-added, crisis management Wait. Through big data conclusions, companies can accurately find customers and realize precise marketing in the true sense. This article starts with the definitions of precision marketing, real estate marketing, and big data marketing, and the possibility and necessity of real estate companies applying big data marketing. Through the actual operation of 
big data precision marketing by real estate companies, it focuses on the analysis of big data in the real estate precision marketing field. Regularize the string attribute variables in the original data set and convert them into different floating-point numbers or integer numbers to facilitate numerical calculations and data analysis so as to facilitate the construction of beautiful and more convincing visualization results, but the flaw is still that there is a lack of deeper mining of massive log data and displaying it more intuitively in the form of charts. Through the operational practice of real estate companies, it is demonstrated that the breakthrough from traditional marketing to precision marketing can be achieved by analyzing customer needs through big data. Big data precision marketing is a large-scale personalized interaction, which is the basis for efficient conversion. Its value lies not in the existence of quantity but in the discovery of value. This value is currently mainly used in analysis and forecasting. 


\section{REFERENCES}

Bauer, E. (2018). Improving operational efficiency of applications via cloud computing. IEEE Cloud Computing, 5(1), 12-19. doi:10.1109/MCC.2018.011791710

Bhadoria, R. S., \& Chaudhari, N. S. (2019). Pragmatic Sensory Data Semantics with Service Oriented Computing. Journal of Organizational and End User Computing, 31(2), 22-36. doi:10.4018/JOEUC.2019040102

Cho, K.-R., \& Cho, S.-B. (2017). A study on the performance and influence of patent development strategy in ict convergence technology using the big data. Advanced Science Letters, 23(12), 12812-12817. doi:10.1166/ asl.2017.10905

Fatima, A., Abbas, A., Ming, W., Zaheer, A. N., \& Akhtar, M.-H. (2017). Analyzing the academic research trends by using university digital resources: A bibliometric study of electronic commerce in china. Universal Journal of Educational Research, 5(9), 1606-1613. doi:10.13189/ujer.2017.050918

Gui, Wu, \& Gong. (2019). Value-added service investment decision of b2c platform in competition. Kongzhi yu Juece/Control and Decision, 34(2), 395-405.

Kim, H. (2019). Investigating the Mediating Role of Social Networking Service Usage on the Big Five Personality Traits and on the Job Satisfaction of Korean Workers. Journal of Organizational and End User Computing, 31(1), 110-123. doi:10.4018/JOEUC.2019010106

Kovalchik, , \& Reid, . (2017). Comparing matchplay characteristics and physical demands of junior and professional tennis athletes in the era of big data. Journal of Sports Science \& Medicine, 16(4), 489-497. PMID:29238248

Li, Guo, Li, Qi, \& Zhang. (2018). Idaas: inter-datacenter network as a service. Academic Press.

Li, Liu, Yang, Hu, Wang, \& Xu. (2017). Predicting inter-data-center network traffic using elephant flow and sublink information. Academic Press.

21. Liang, , Ding, , Huang, , \& Deng, . (2018). Traditional chinese medicine data management policy in big data environment. Zhongguo Zhongyao Zazhi, 43(4), 840-846. PMID:29600663

Liu, X.-F., \& Zhan, Z.-H. (2018). An energy efficient ant colony system for virtual machine placement in cloud computing. IEEE Transactions on Evolutionary Computation, 22(1), 113-128. doi:10.1109/TEVC.2016.2623803

Losing, Hammer, \& Wersing. (2018). Tackling heterogeneous concept drift with the self adjusting memory (sam). Knowledge and Information Systems, 54(1), 171-201.

Luo. (2018). Intelligent led lighting centralized control system based on internet of things. Shenyang Gongye Daxue Xuebao/Journal of Shenyang University of Technology, 40(4), 453-458.

Munshifwa, Makashini-Masiba, \& Chileshe. (2018). Exploring the interface between formal and informal real estate markets in facilitating legally binding transactions in Zambian cities. Urban Forum, 29(1), 19-32.

Nantembelele, F. A., \& Gopal, S. (2018). Assessing the challenges to e-commerce adoption in tanzania. Global Business and Organizational Excellence, 37(3), 43-50. doi:10.1002/joe.21851

Navarro-Méndez, Carrera-Suárez, Sánchez-Escuderos, Cabedo-Fabrés, Baquero-Escudero, \& Gallo. (2017). Wideband double monopole for mobile, wlan, and c2c services in vehicular applications. Academic Press.

Nezami, M., Worm, S., \& Palmatier, R. (2018). Disentangling the effect of services on b2b firm value: Tradeoffs of sales, profits, and earnings volatility. International Journal of Research in Marketing, 35(2), 205-223. doi:10.1016/j.ijresmar.2017.12.002

Otterness. (2017). Incorporating foam into medical student and resident education. Academic Press.

Peng, R., Zhang, M., Guo, C., Cui, J., \& Song, J. (2018). Public bicycle operating system based on space-time security and the internet of things. Wuhan University Journal of Natural Sciences, 23(6), 541-548. doi:10.1007/ s11859-018-1360-8

Prisha, P., Neo, H.-F., Ong, T.-S., \& Teo, C.-C. (2017). E-commerce security and identity integrity: The future of virtual shopping. Journal of Computational and Theoretical Nanoscience, 23(8), 7849-7852. 
Wei, C. L., \& Ho, C. T. (2019). Exploring Signaling Roles of Service Providers\&apos; Reputation and Competence in Influencing Perceptions of Service Quality and Outsourcing Intentions. Journal of Organizational and End User Computing, 31(1), 86-109. doi:10.4018/JOEUC.2019010105

Xiao, S., Ma, S.-H., Li, G., \& Mukhopadhyay, S. K. (2017). European option pricing with a fast fourier transform algorithm for big data analysis. IEEE Transactions on Industrial Informatics, 12(3), 1219-1231. doi:10.1109/ TII.2015.2500885

Yong-zhang, Z., Pei-xing, L., Shu-gong, W., Fan, X., Jing-zhe, L., \& Le, G. (2017). Research progress on big data and intelligent modelling of mineral deposits. Bulletin of Mineralogy. Petrology and Geochemistry, 36(2), $327-331$.

Zhu, W.-Q., \& Zhong, Y.-S. (2017). Trustworthiness recommendation for o2o service providers based on their reputation. Yingyong Kexue Xuebao. Journal of Applied Sciences, 35(5), 585-601. 